\title{
Farklı Yaş Gruplarında Bizigomatik Genişlik, Maksilla ve Foramen Magnumda Cinsiyete Bağlı Değişiklikler
}

\author{
Esra Yeşilova(0000-0003-1800-9583) ${ }^{\alpha}$
}

Selcuk Dent J, 2021; 8: 156-162 (Doi: 10.15311/selcukdentj.890593)

Bašvuru Tarihi: 03 Mart 2021 Yayına Kabul Tarihi: 22 Mart 2021

Öz

Farklı Yaş Gruplarında Bizigomatik Genișlik, Maksilla ve Foramen Magnumda Cinsiyete Bağlı Değişiklikler

Amaç: Bu çalışmanın amacı farklı dekatlarda kişilere ait konik ışınlı bilgisayarlı tomografi (KIBT) görüntülerinde kafa tabanından elde edilen ölçüm ve değerlendirmelerle cinsiyetin ilişkisinin değerlendirilmesidir.

Gereç ve Yöntemler: Çalışma, beş farklı dekattan (20-29, 30-39, 40-49, 50-59 ve 60-69 yaş aralıklarında) eşit sayıda olmak üzere toplam 100 kişinin KIBT görüntüleri üzerinde yapıldı. Foramen magnumun tipinin değerlendirilmesi için 8 kategorili bir sınıflama kullanıldı. Foramen magnum boyutları ile maksiller alveoler alan boyutları transversal ve sagital, bizigomatik genişlik ise transversal yönde ölçüldü. Ölçüm ve değerlendirmeler, KIBT cihazının kendi yazıımında iki kez tekrarlandı. Verilerin istatistik analizi IBM SPSS Statistics 21.0 programında yapıldı. İstatistiksel önemlilik için $p<0.05$ değeri kriter kabul edildi.

Bulgular: Erkeklerde "hegzagonal", kadınlarda ise "yumurta şeklinde" foramen magnum en sık izlenen tiplerdi. Bununla birlikte cinsiyetin foramen magnum tipleri dağılımı üzerinde etkisi görülmedi $(p=0.841)$. Ölçümü yapılan diğer tüm parametreler ve cinsiyet değişkeninin arasında anlamlı fark olduğu görüldü (her bir değişken için $p<0.05$ ).

Sonuç: Radyolojik verilerin adli bilimlerde önemi giderek artmaktadır. Cinsiyet belirlenmesinde KIBT verilerinin, anatomik ve BT çalışmaları verileri ile uyumlu olduğu görülmüştür. Ağız, diş ve çene radyolojisinin sadece hastalıkların teşhisinde, tedavi ve prognoz takiplerinde değil adli bilimlerde de önemli katkıs olacağı ön görülmektedir.

\section{ANAHTAR KELIMELER}

Adli bilimler, Radyoloji, Konik ışınlı bilgisayarı tomografi, Kafa tabanı, Cinsiyet

Radyoloji, yapılarındaki mineraller nedeniyle maruz kaldıkları X ışınlarını absorbe ederek yüksek dansiteli görüntüler oluşturan diş ve kemiklerin değerlendirilmesinde önemli bir yere sahiptir. Morfolojik değişimler, patolojiler, anatomik varyasyonlar ile büyüme ve gelişimin etkileri radyografik olarak tespit ve takip edilebilmektedir., ${ }^{1,2}$ Görüntülerden elde edilen veriler hastalıkların saptanmasında, tedavi takiplerinde diagnostik amaçla olduğu kadar antropolojik araştırmalar ${ }^{3}$ ve adli bilimlerde $e^{4,5}$ de doğrulayıcı ve rehberlik edici amaçlarla da kullanılmaktadır.

Ağız içi ve dışı radyografilerle, dişler ve ilgili yapıların

\section{ABSTRACT}

Gender Related Changes of Bizygomatic Diameter, Maxilla and Foramen Magnum in Different Age Groups

Background: The purpose of this study was to assess the relationship between gender and the measurements/evaluations acquiered from skull base on cone beam computed tomography images in people at different decades.

Methods: The study was performed on $100 \mathrm{CBCT}$ images of the subjects in five different decades (age-ranged between 20-29, $30-39,40-49,50-59$ and 60-69). A classification in eight categories was used for the categorisation of foramen magnum type. The dimensions of foramen magnum and maxillary alveolar region measured transversally and sagitally. Byzigomatic width measured transversally. The evaluations were repeated twicely. Data was analyzed in IBM SPSS Statistics 21.0. For statistically significance, $p<0.05$ was accepted as criteria.

Results: In males "hegzagonal" type, in females "egg shaped" type was the most common forms. However, gender has no effect on the distribution of foramen types $(p=0.841)$. Statistically significant difference was found between gender and all other measurements ( $p<0.05$ for each one).

Conclusion: The importance of radiologic data in forensic sciences is increasing. It was observed that data obtained from CBCT was compatible with data achieved from anatomic and CT studies using for determination of gender. It is foreseen that oral and maxillofacial radiology has an important contribution not only in the diagnosis of diseases, treatment and following of prognosis but also in forensic sciences.

\section{KEYWORDS}

Forensic sciences, Radiology, Cone beam computed tomography, Skull base, Gender

ölüm öncesi ve sonrası kayıtlarının karşılaştııılarak kimlik ve yaş belirleyiciliğinde kullanılması adli bilimlerin değerli bir veri kaynağını oluşturur. ${ }^{4}$ Radyoloji, teknolojik gelişmelerin modern tıbba yansıdığı önemli bir bilim dalıdır. Bilgisayar teknolojilerinde gelişmelerle dijital sistemler ve üç boyutlu görüntüler rutin radyolojik işlemler arasında yer almıştır. "Sanal antropoloji" olarak tanımlanan yeni bir araştırma alanı; yaşayan ve ölmüş kişilerde yaş, cinsiyet, coğrafik köken ve boya ait verileri tahmin etmek için radyolojide kullanılan görüntüleme tekniklerini antropolojik kriterlerle birleştirmektedir. ${ }^{6}$

Kafatası \%92 doğruluk oranıyla, pelvisten sonra

\footnotetext{
${ }^{\alpha}$ Eskişehir Osman Gazi Üniversitesi Diş Hekimliği Fakültesi Ağız Diş ve Çene Radyolojisi AD, Eskişehir, Türkiye
} 
cinsiyet belirleyiciliğinde kullanılan ikinci vücut bölgesidir. ${ }^{7}$ Foramen magnum oksipital kemikte bulunan; fiziksel hasara dirençli, kalın ve korunabilir formda bir anatomik yapıdır. Bu nedenle kafatasında önemli bir anatomik landmarktır. ${ }^{8}$ Fossa cranii posterior ile canalis vertebralisi birbirine bağlar. $^{9}$ Cinsiyet belirleyiciliğinde ise farklı ülkelerden çok araştırmacı tarafından çalışılmıştır. ${ }^{10}$ Bununla birlikte Arnold Chiari gibi çeşitli nörolojik patolojilerin prognoz ve tedavisinde, ${ }^{11}$ intra ve extradural tümörlere yaklaşımda, servikal vertebra ile ilişkili romatolojik hastalıklarda ${ }^{12}$ ve akondroplazi gibi stenozuna neden olan durumlar ${ }^{13}$ açısından da klinik öneme sahiptir.

Foramen magnum şekilleri de bazı araştırmacılar ${ }^{12,14,15}$ tarafından gruplandırımıştır. Şekillere göre numaralandırmalar farklı olmakla beraber "farklı çevre uzunluklu iki halkanın kombini”, "yuvarlak", "oval", "dörtgen", "beşgen", "altıgen", "yumurta şekilli" ve "düzensiz şekilli" isimli alt tipler sınıflamalarda tanımlanmıştır. Gövsa ve ark..$^{12}$ yaptıkları çalışmada foramen magnumu şekilsel olarak tanımlayıp anteriordaki açının ve kavsin genişliğine göre "farklı çevre uzunluklu iki halkanın kombini", "yuvarlak", "altıgen", "oval" tipleri geniş; "dörtgen", "yumurta şekilli", "beşgen" tipleri dar ve "düzensiz" tipi geniş ama asimetrik olarak gruplandırmış ve cerrahi açıdan hayati risk taşıyabilecek bu noktaya dikkat çekmişlerdir.

Cinsiyet belirlemeye yönelik değerlendirmelerde foramen magnum ${ }^{10}$ ile birlikte kraniyum ve mandibula da çalışılmıştı. $7,11,16,17,18,19$ Anatomik ve tomografik kesitlerle yapılan bu değerlendirmelerde seksüel dimorfizm yanında anatomik yapıların altın oranı, Türk popülasyonuna ait spesifik kraniomorfometrik data oluşturulması gibi sonuçlara da ulaşıldığı görülmektedir. Bununla birlikte foramen magnum şeklinin kafa tabanına ait kantitatif ölçümlerle ilişkisi ile ilgili bir çalışmaya literatürde rastlanmadı. Konik ışınlı bilgisayarlı tomografiden (KIBT) elde edilen verilerin de bu çalışmalarda kullanıldığı görülmektedir. ${ }^{16,19}$ KIBT; hızlı tarama süresi, yüksek çözünürlüklü görüntüleri ve bilgisayarlı tomografiye (BT) göre pratik ekipmanı ile kraniometrik araştırmalarda da kullanım alanı bulmuştur. ${ }^{19}$ Bahsedilen sebepler baz alınarak farklı dekatlardaki kişilere ait konik ışını bilgisayarlı tomografi görüntülerinde, kafa tabanında yapılan ölçüm ve değerlendirmelerle cinsiyetin ilişkisinin değerlendirilmesi amacıyla bu çalışma tasarlandı.

\section{GEREÇ VE YÖNTEMLER}

Eskişehir Osmangazi Üniversitesi Girişimsel Olmayan Klinik Araştırmalar Etik Kurul Başkanlığı'nın 30.12.2020 tarih ve 17 nolu kararılya bu çalışmanın yapılması etik ve bilimsel açıdan uygun olarak bulunmuştur. Çalışmadaki tüm prosedürler, kurumsal ve/veya ulusal etik araştırma komitesinin etik standartlarına ve 1964 Helsinki Deklerasyonu ile daha sonra yapilan değişiklikler ve karşılaştırılabilir etik standartlara uygun olarak yapılmıştır.

$\mathrm{Bu}$ retrospektif çalışma için Eskişehir Osmangazi Üniversitesi Diş Hekimliği Fakültesi, Ağız Diş ve Çene Radyolojisi AD. Arşivine kayıttl; 2016 Mayıs ve 2020 Aralık Ayları arasında çekilmiş dijital konik ışınlı bilgisayarlı tomografi görüntüleri tarandı. Çalışma grubu her bir dekat ve cinsiyette 10'ar tane olmak üzere 3. (2029), 4. (30-39), 5. (40-49), 6. (50-59) ve 7. (60-69) dekatlarda toplam 100 kişiye ait imajlar rastgele seçilerek oluşturuldu. Tomografik görüntülerin tamamı maksilla, zigomatik kemik ve foramen magnumun izlenebildiği farklı görüntüleme alanlarında, diagnostik açıdan kaliteli ve çalışma alanında patoloji içermeyen $0.400 \mathrm{~mm}$ voxel boyutunda kesitlerden oluşmakta idi (ProMax 3D Mid; Planmeca, Helsinki/Finland) (Expojur parametreleri $94 \mathrm{kV}$ ve $14 \mathrm{~mA}$ ).

Tomografi görüntüleri üzerinden görüntüleme yazııımı (Romexis 4.6.2.R) ile aşağıdaki ölçüm ve değerlendirmeler yapıldı:

1. Foramen magnum uzunluğu ve genişliği ölçüldü, foramen şekli kategorik olarak değerlendirildi.

a. Foramen şeklinin sınıflaması için Gövsa ve ark. ${ }^{12}$ sınıflaması kullanıldı. Bu sınıflamaya göre foramen magnum, 8 alt kategoride oluşmaktadır. Bu kategoriler sırasıyla tip 1 (farklı çevre uzunluklu iki halkanın kombini) (Resim 1-a), tip 2 (tetragonal-dörtgen) (Resim 1-b), tip 3 (yumurta şeklinde) (Resim 1-c), tip 4 (yuvarlak) (Resim 1-d), tip 5 (hegzagonalaltıgen) (Resim 1-e), tip 6 (oval) (Resim 1-f), tip 7 (irregüler-düzensiz) (Resim 1-g) ve tip 8 (pentagonal-beşgen) idi.

b. Foramen magnumun uzunluğu basion ve opisthion arası mesafe, genişliği ise foramenin en geniş lateral kurvatür noktalarında lateral kenarlar arası mesafe olarak ölçüldü (Resim 2a ve 2-b).

2. Bizigomatik genişlik sağ ve solda zygion noktaları arasından (Resim 2-c) ölçüldü.

3. Maksiller alveoler genişlik sağ ve solda ectomolare (Resim 2-d); uzunluk prosthion ve alveolon noktaları arasından (Resim 2-e) ölçüldü.

Arşivin taranması, ölçüm ve kategorizasyon işlemleri; ağız diş ve çene radyolojisinde yirmi yıldır tecrübeli olan uzman tarafından (EY), aynı bilgisayar ekranında ve optimum inceleme koşullarında yapıldı. 


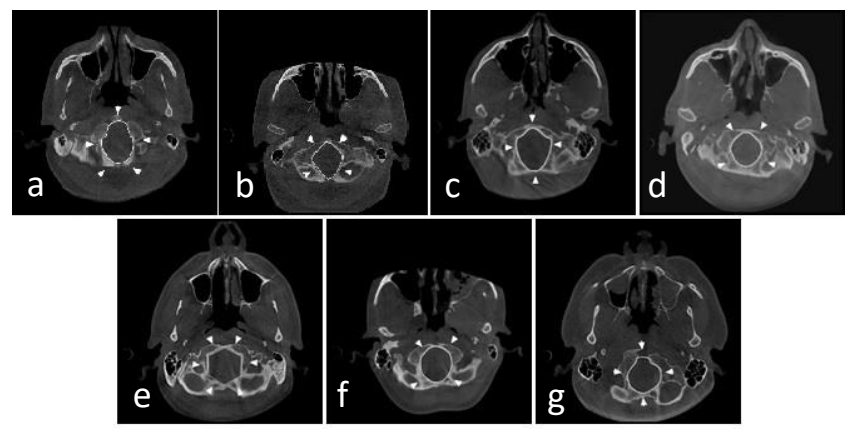

Resim 1

Foramen magnum şeklinin sınıflandırılması (Gövsa ve ark 2011) a: Tip 1 (farklı çevre uzunluklu iki halkanın kombini), b: Tip 2 (tetragonal-dörtgen), c: Tip 3 (yumurta şeklinde), d: Tip 4 (yuvarlak), e: Tip 5 (hegzagonal-altıgen), f: Tip 6 (oval), g: Tip 7 (irregülerdüzensiz)
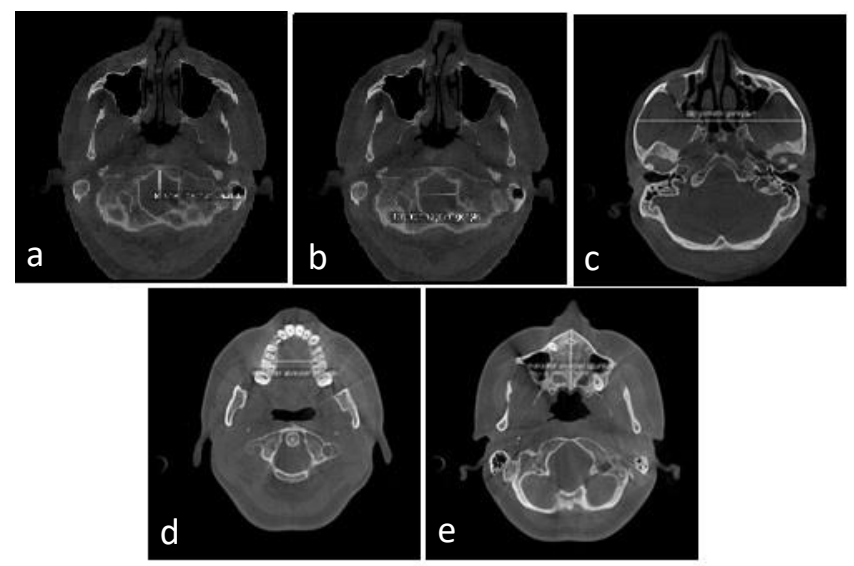

Resim 2

Yapılan ölçümlerin tomografik kesitlerde gösterilmesi

a: Foramen magnum uzunluğu, b: Foramen magnum genişliği, c: Bizigomatik genişlik, d: Maksiller alveoler genişlik, e: Maksiller alveoler uzunluk

\section{ISTATISTIKSEL DEĞERLENDIRME}

Sürekli veriler ortalama \pm standart sapma; kategorik veriler ise yüzde (\%) olarak verildi. Verilerin normal dağılıma uygunluğunun araştırımasında Shapiro Wilk's testinden yararlanıldı. Normal dağıım gösteren grupların karşılaştııımasında; grup sayısı iki olan durumlar için bağımsız örnek $t$ testi analizi, grup sayısı üç ve üzerinde olan durumlar için tek yönlü varyans analizi (One-Way ANOVA) kullanıldı. Değişkenler arası ilişkinin (korelasyon) yön ve büyüklüğünün belirlenmesi amacıyla normal dağılım gösteren değişkenlerde Pearson korelasyon katsayıları, normal dağılıma uygunluk göstermeyen değişkenler için ise Spearman korelasyon katsayıları hesaplandı. Foramen magnum şekline ait iki değerlendirme arasında uyumun belirlenmesi için Cohen Kappa katsayıSı hesaplandı. Analizler IBM SPSS Statistics 21.0 (IBM Corp. Released 2012. IBM SPSS Statistics for Windows, Version 21.0. Armonk, NY: IBM Corp.) programında yapıldı. İstatistiksel önemlilik için $p<0.05$ değeri kriter kabul edildi.

\section{BULGULAR}

Foramen magnum şekli

Her iki gözlemde de pentagonal (beşgen-tip 8) tipte foramen magnum izlenmedi. Tip 1 ve 7 foramen magnumdan sadece birer tane mevcut olup her iki gözlemde de aynı kategoride değerlendirildi. Yumurta şeklinde tip 3, 38 olguda; hegzagonal formda tip 5 ise 34 olguda her iki gözlemde de aynı tipte ve en sık değerlendirilen iki tip foramen magnumdu $(p<0.001)$. Tip 2 ve 4 beşer olguda, tip 6 ise 11 olguda iki gözlemde de aynı şekilde izlendi. Beş olgu ise iki gözlemde farklı tiplerde bildirildi.

İki gözlemin uyumu değerlendirildiğinde \%91,7 ve $\mathrm{p}<0.001$ ile mükemmel uyum izlendi. Bu nedenle sürekli verilerin karşılaştırıması ilk gözlem ile yapıldı.

Cinsiyetin, foramen magnum tiplerinin dağılımı üzerinde herhangi bir etkisi görülmedi $(p=0.841)$. Bununla beraber erkeklerde $\% 54,1$ oranında hegzagonal (tip 5), kadınlarda ise $\% 52,6$ oranında yumurta şeklinde (tip 3) foramen magnum en sık izlenen tiplerdi.

Foramen magnum, maksiller alveoler alan ve bizigomatik genişlik

Ölçümle elde edilen tüm verilere Shapiro Wilk testi uygulandı. Verilerin normal dağılıma uygunluk gösterdiği görüldü $(p<0.05)$. Her iki gözlemden elde edilen foramen uzunluk ve genişliği, maksiller alveoler uzunluk ve genişlik ile bizigomatik genişlik değerlerinin Spearman korelasyon testine göre ilişki katsayıları hesaplandı. Sonuçlar foramen magnum genişliği için $r=0.918(p<0.001)$, foramen uzunluğu için $r=0.965$ $(p<0.001)$, maksiller alveoler genişlik için $r=0.937$ $(p<0.001)$, maksiller alveoler uzunluk için $r=0.948$ $(p<0.001)$ ve bizigomatik genişlik için ise $r=0.990$ $(p<0.001)$ idi. Ilişki katsayıları \%90 üzerinde olduğu için iki ölçümün aritmetik ortalaması alındı. Değerler ayrı sütunlarda isimlendirilerek değerlendirme ve karşılaştırmalar için kullanıldı (Tablo 1).

Tablo 1.

\section{Kafa tabanı ölçümleri}

\begin{tabular}{|c|c|}
\hline & Ort $\pm s s^{3}$ \\
\hline & $\begin{array}{l}\text { Min-Max4 } \\
(n=100)\end{array}$ \\
\hline F. Magnum ${ }^{1}$ Genişlik & $\begin{array}{l}31.5 \pm 2.61 \\
24.8-38.6\end{array}$ \\
\hline F. Magnum Uzunluk & $\begin{array}{l}36.0 \pm 2.5 \\
30.0-41.6\end{array}$ \\
\hline M. Alveoler ${ }^{2}$ Genişlik & $\begin{array}{l}56.4 \pm 3.32 \\
50.4-66.0\end{array}$ \\
\hline M. Alveoler Uzunluk & $\begin{array}{l}47.9 \pm 2.88 \\
41.7-55.6\end{array}$ \\
\hline Bizigomatik Genişlik & $\begin{array}{l}124 \pm 5.97 \\
112-140\end{array}$ \\
\hline
\end{tabular}

${ }^{3}$ Ortalama \pm Standart Sapma, ${ }^{4}$ Minimum ve Maximum Değerler Ölçümler mm cinsinden verilmiştir. 
Foramen magnum tipleri ile ölçümü yapılan diğer parametreler arasında herhangi bir ilişki izlenmedi (Tablo 2).

Tablo 2.

\section{Foramen magnum tipleri ve kafa tabanı ölçümleri}

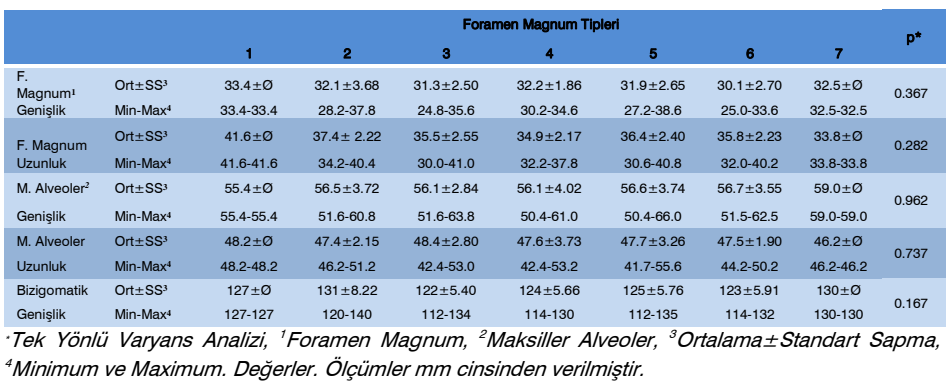

Yaş değişkeni (dekat olarak) ile ölçümlerin arasında istatistik açıdan anlamlı fark olmadığı görüldü (her biri için $p>0.05$ ) (Tablo 3).

Tablo 3.

\section{Dekatlara göre kafa tabanı ölçümleri}

\begin{tabular}{|c|c|c|c|c|c|c|c|}
\hline & \multicolumn{7}{|c|}{ YAŞ GRUPLARI } \\
\hline & & 20-29 yaş & 30-39 yaş & 40-49 yaş & $50-59$ yaş & 60-69 yaş & \\
\hline & & (3. Dekat) & (4. Dekat) & (5. Dekat) & (6. Dekat) & (7. Dekat) & $\mathrm{p}^{*}$ \\
\hline & & $(n=20)$ & $(n=20)$ & $(n=20)$ & $(n=20)$ & $(n=20)$ & \\
\hline F. Magnum ${ }^{1}$ & Ort $\pm S S^{3}$ & $32.4 \pm 2.14$ & $32.0 \pm 2.63$ & $30.8 \pm 2.84$ & $31.4 \pm 2.99$ & $31.0 \pm 2.25$ & 0.196 \\
\hline Genişlik & Min-Max ${ }^{4}$ & 29.4-37.8 & 28.4-38.6 & $25.6-36.4$ & $24.8-35.8$ & 28.2-35.4 & \\
\hline F. Magnum & Ort $\pm S S$ & $37.0 \pm 2.46$ & $35.8 \pm 2.37$ & $35.3 \pm 2.25$ & $36.0 \pm 2.85$ & $35.7 \pm 2.42$ & 0.248 \\
\hline Uzunluk & Min-Max & $33.0-41.0$ & $30.6-39.6$ & $31.4-40.0$ & $30.0-41.6$ & $32.0-40.8$ & \\
\hline M. Alveoler ${ }^{2}$ & Ort $\pm S S$ & $57.5 \pm 3.44$ & $55.8 \pm 2.96$ & $56.3 \pm 3.32$ & $55.5 \pm 2.84$ & $57.0 \pm 3.85$ & 0.294 \\
\hline Genişlik & Min-Max & $50.4-63.0$ & $51.6-63.6$ & $51.5-65.6$ & $50.4 \pm 60.8$ & $50.6-66.0$ & \\
\hline M. Alveoler & Ort $\pm S S$ & $47.3 \pm 2.85$ & $47.3 \pm 2.56$ & $48.2 \pm 3.10$ & $48.5 \pm 2.44$ & $48.3 \pm 3.39$ & 0.475 \\
\hline Uzunluk & Min-Max & $41.7-52.8$ & $42.4-52.4$ & $42.4-53.2$ & $44.2-53.2$ & $42.6-55.6$ & \\
\hline Bizigomatik & Ort $\pm S S$ & $123 \pm 5.46$ & $125 \pm 7.26$ & $124 \pm 4.44$ & $123 \pm 7.30$ & $123 \pm 5.13$ & 0.737 \\
\hline Genişlik & Min-Max & $114-136$ & $112-135$ & $116-134$ & $113-140$ & $114-133$ & \\
\hline
\end{tabular}

*Tek Yönlü Varyans Analizi, ${ }^{1}$ Foramen Magnum, ${ }^{2}$ Maksiller Alveoler, ${ }^{3}$ Ortalama \pm Standart Sapma, ${ }^{4}$ Minimum ve Maximum Değerler. Ölçümler mm cinsinden verilmiştir.

Cinsiyet değişkeni ile foramen magnum genişliği $(p<0.001)$, foramen magnum uzunluğu $(p<0.001)$, maksiller alveoler genişlik $(p=0.002)$, maksiller alveoler uzunluk $(p<0.001)$ ve bizigomatik genişlik $(p<0.001)$ ölçüm parametreleri arasında anlamlı fark olduğu görüldü (Tablo 4).

Tablo 4.

\section{Cinsiyete göre kafa tabanı ölçümleri}

\begin{tabular}{|c|c|c|c|}
\hline \multicolumn{4}{|c|}{ Ort $\pm S s^{3}$} \\
\hline & Kadin $(n=50)$ & Erkek $(n=50)$ & \\
\hline F. Magnum ${ }^{1}$ & $30.5 \pm 2.22$ & $32.5 \pm 2.63$ & $<0.001$ \\
\hline Genişlik & $24.8-35.0$ & 26.4-38.6 & \\
\hline F. Magnum & $34.9 \pm 2.15$ & $37.0 \pm 2.39$ & $<0.001$ \\
\hline Uzunluk & $30.0-39.4$ & $33.0-41.6$ & \\
\hline M. Alveoler ${ }^{2}$ & $55.4 \pm 2.98$ & $57.4 \pm 3.37$ & 0.002 \\
\hline Genişlik & $50.4-64.0$ & $50.4-66.0$ & \\
\hline M. Alveoler & $46.8 \pm 2.80$ & $49.0 \pm 2.54$ & $<0.001$ \\
\hline Uzunluk & $41.7-53.0$ & $44.6-55.6$ & \\
\hline Bizigomatik & $120 \pm 4.21$ & $127 \pm 5.19$ & $<0.001$ \\
\hline Genişlik & $112-128$ & $117-140$ & \\
\hline
\end{tabular}

${ }^{3}$ Ortalama \pm Standart Sapma, ${ }^{4}$ Minimum ve Maximum Değerler, Ölçümler mm cinsinden verilmiştir.
Foramen magnum genişliği $(r=-0.183, p=0.068)$, foramen magnum uzunluğu $(r=-0.125, p=0.217)$, maksiller alveoler genişlik $(r=-0.088, p=0.384)$ ve bizigomatik genişlik $(r=-0.055, p=0.589)$ verileri ile genel yaş dağııımı arasında korelasyon testi sonuçlarına göre istatistik açıdan anlamlı olmamakla beraber ters yönlü bir ilişki olduğunu gösterilmiştir.

Tüm ölçümlerin birbirleri ile ilişkileri de korelasyon analizi ile değerlendirildi. Bizigomatik genişlik ile foramen magnum genişliği $(r=0.497, p<0.001)$, foramen magnum uzunluğu $(r=0.436, p<0.001)$, maksiller alveoler genişlik $(r=0.405, p<0.001)$ ve maksiller alveoler uzunluk $(r=0.342, p<0.001)$ arasında; foramen magnum genişliği ile uzunluğu $(r=0.658, p<0.001)$ arasında ve maksiller alveoler genişlik ile uzunluk $(r=0.4 .11, p<0.001)$ arasında aynı yönde, çok güçlü ilişki izlendi. Maksiller alveoler uzunluk ve foramen magnum uzunluğu $(r=0.313, p=0.002)$ arasında aynı yönde, güçlü ilişki izlendi.

\section{TARTIŞMA}

$\mathrm{Bu}$ çalışmada KIBT görüntülerinde foramen magnum tipleri, boyutları ve cinsiyet değişkeni ile ilişkisi farklı yaş gruplarında değerlendirildi. Foramen magnum kategorizasyonu için Türk popülasyonunda yapılmış, şekillerin detaylandırıldığı Gövsa ve ark'ının ${ }^{12}$ sınıflaması kullanıldı. Gövsa ve ark. ${ }^{12}$, çalışma gruplarını cinsiyet değişkenine göre ayırmadan kuru kafalar ve oksipital kemikler üzerinde değerlendirme yapmışlardır. Sonuçta sırasıyla tip 2 (tetragonal), 1 (farklı çevre uzunluklu iki halkanın kombini), 5 (hegzagonal) ve 3 (yumurta şeklinde) en sık görülen foramen magnum tipleri olarak rapor edilmiştir. Bu çalışmada ise en sık görülen foramen magnum tipleri sırasıyla tip 3 ve 5 idi. Eşit sayıda kadın ve erkeğe ait görüntüler değerlendirilmiştir. Erkeklerde tip 5, kadınlarda ise tip 3 sık gözlenmiş olup cinsiyetin foramen magnum şeklinin değişimi üzerine bir etkisi yoktur. Ayrıca yüksek gözlemci uyumu $(\% 91,7)$ nedeniyle, mevcut sınıflamanın şekilsel tanımlamalarının tekrarlanabilir yeterlikte olduğu düşünülmektedir.

KIBT ile yapılan başka bir çalışmada ${ }^{20}$, her biri eşit sayıda kişi içermemekle beraber farklı yaş gruplarında foramen magnum morfometrisi ile iliş̧ili değerlendirme yapılmıştır. Cinsiyetler arasında şekilsel açıdan bir fark izlememiş olmalarına rağmen kadınlarda "yuvarlak" tipin erkeklerde ise "hegzagonal" tipin en yaygın tipler olduğunu bildirmişlerdir. Bu çalışmada da benzer şekilde hegzagonal tip erkeklerde en yaygın olarak izlenen foramen magnum tipidir. Ulcay ve ark. ${ }^{11}$ "oval", Chethan ve ark. ${ }^{13}$ ile Murshed ve ark. ${ }^{15}$ "yuvarlak", Sindel ve ark. ${ }^{14}$ "yuvarlak köşeli tetragonal" tipte foramen magnumların çalışmalarında sık olduğunu bildirmiş̧erdir. Her 
çalışmada farklı foramen tiplerinin daha sık görülüyor olması insidanslarının ve şekillerinin değişkenlik gösterdiğini, bu nedenle özellikle cerrahi operasyonlardan önce dikkatle morfolojik değerlendirme yapılması gerektiğini düşündürmektedir.

Cerrahi, nöroloji, romatoloji ve adli bilimler açısından önemli bir yere sahip olan foramen magnum için makroskopik inceleme, BT ve KIBT ile ölçüm ve kategorizasyonlar yapılmıştır. Foramen magnum genişliği, uzunluğu ve şekli ile ilgili bu çalışmanın literatürle karşılaştırılması Tablo 5'te verilmiştir. Çalışmanın ortalama değerlerinin, literatürde ${ }^{7-22}$ rapor edilen verilerle benzer aralıkta olduğu görülmektedir. Bilgiler ışığında, anatomik verilerle tomografik verilerin karşılaştırılması gerektiği dikkat çekmektedir. Cinsiyeti bilinen kuru kafaların tomografi değerlendirmelerinin yapılıp sanal antropoloji için veri havuzu oluşturulması, ölüm sonrası değerlendirmeler için daha doğru veriler sağlayacaktır.

Foramen magnum uzunluğu ve genişliğinin cinsiyet açısından belirleyici bir faktör olduğu görülmüştür (Tablo 4). Erkeklerde ölçülen değerler kadınlara göre anlamlı derecede farklı olarak bulunmuştur $(p<0.001)$. Sonuçlar literatürle $\mathrm{e}^{7-10,15-22}$ uyumludur.

Bizigomatik genişlik ortalama değerleri; 18-45 yaş grubunda bir BT çalışması yapmış olan Ekizoğlu ve ark. ${ }^{7}$ tarafından kadınlarda $122.9 \pm 4.7 \mathrm{~mm}$, erkeklerde $131.8 \pm 5.1 \mathrm{~mm}$ olarak rapor edilmiştir. Cappella ve ark. ${ }^{18}$ kuru kafalar üzerinde 24-90 yaş aralığında yaptıkları anatomik araştırmada ortalama bizigomatik genişliği kadınlarda $124 \pm 4 \mathrm{~mm}$, erkeklerde 129 $\pm 6 \mathrm{~mm}$ olarak bildirmişlerdir. Bu çalışmada ise kadınlarda ortalama $120 \pm 4.21 \mathrm{~mm}$, erkeklerde ortalama $127 \pm 5.19 \mathrm{~mm}$ bizigomatik genişlik hesaplanmıştır. Bu çalışma yaş grupları arasında ölçümler açısından bir farkın olmadığını göstermiştir (Tablo 3). Üç çalışmadaki değerler benzer aralıktadır. Ayrıca üç çalışmada da cinsiyetler arasında anlamlı farkın izlendiği görülmektedir (her biri için $p<0.001$ ). Kadın ve erkekler arasında anlamlı farkın $(p=0.000)$ görüldüğü, 18-50 yaş arasında kuru kafalar üzerinde yapılan bir radyografik değerlendirmede ${ }^{17}$ yukarıda bahsedilen çalışmalardan oldukça yüksek değerler bulunmuştur. Kadınlar için $141.97 \pm 7.27 \mathrm{~mm}$, erkekler için $152.27 \pm 5.59 \mathrm{~mm}$ olarak rapor edilmiştir.

Tablo 5.

\section{Cinsiyete göre kafa tabanı ölçümleri}

\begin{tabular}{|c|c|c|c|c|c|c|c|c|}
\hline & \multirow{2}{*}{$\begin{array}{l}\text { Inceleme } \\
\text { Yöntemi }\end{array}$} & \multicolumn{2}{|c|}{ Kadin / Ort $\pm S^{1}$} & \multicolumn{2}{|c|}{ Erkek / Ort $\pm S S$} & \multicolumn{2}{|c|}{ Genel / Ort \pm Ss } & \multirow[b]{2}{*}{ (n) } \\
\hline & & F.M. ${ }^{2}$ Genişlik & F.M. Uzunluk & F.M. Genişlik & F.M. Uzunluk & F.M. Genişlik & F.M. Uzunluk & \\
\hline $\begin{array}{l}\text { Yeşilova } 2021 \text { (Mevcut } \\
\text { çalışma) }\end{array}$ & $\begin{array}{l}\text { Dijital KIBT }{ }^{3} \\
\text { (Retrospektif) }\end{array}$ & $30.5 \pm 2.22$ & $34.9 \pm 2.15$ & $32.5 \pm 2.63$ & $37.0 \pm 2.39$ & $31.5 \pm 2.61$ & $36.0 \pm 2.5$ & 100 \\
\hline Ekizoğlu ve ark. 2016 & $\begin{array}{l}\text { Dijital } \mathrm{BT}^{4} \\
\text { (Retrospektif) }\end{array}$ & $29.6 \pm 2.0$ & $34.6 \pm 2.1$ & $31.2 \pm 2.2$ & $36.3 \pm 2.7$ & - & - & 400 \\
\hline Tellioğlu ve ark. 2018 & Dijital BT (Retrospektif) & $28.4 \pm 2.72$ & $32.99 \pm 2.65$ & $30.47 \pm 2.25$ & $34.73 \pm 2.21$ & $29.48 \pm 2.68$ & $33.86 \pm 2.58$ & 100 \\
\hline $\begin{array}{l}\text { Güneş ve Vatansever } \\
2018\end{array}$ & Dijital BT (Retrospektif) & $29.25 \pm 2.1$ & $34.72 \pm 2.57$ & $30.79 \pm 2.27$ & $36.29 \pm 2.89$ & - & - & 313 \\
\hline Meral ve ark. 2020 & Dijital BT (Retrospektif) & $29.98 \pm 2.43$ & $34.76 \pm 2.64$ & $32.75 \pm 2.46$ & $37.54 \pm 2.86$ & - & - & 600 \\
\hline Ulcay ve ark. 2021 & $\begin{array}{l}\text { Anatomi } \\
\text { (Dijital Kumpasla) }\end{array}$ & - & - & - & - & $28.14 \pm 1.77$ & $35.81 \pm 7.56$ & 60 \\
\hline Gövsa ve ark. 2011 & $\begin{array}{l}\text { Anatomi } \\
\text { (Dijital Kumpasla) }\end{array}$ & - & - & - & - & $30.8 \pm 2.9$ & $37.2 \pm 3.5$ & 352 \\
\hline Chetnan ve ark. 2012 & $\begin{array}{l}\text { Anatomi } \\
\text { (Sürmeli Kumpasla) }\end{array}$ & - & - & - & - & $25.2 \pm 2.4$ & $31 \pm 2.4$ & 53 \\
\hline Murshed ve ark. 2003 & $\begin{array}{l}\text { BT } \\
\text { (Milimetrik kumpasla) }\end{array}$ & $29.3 \pm 2.19$ & $34.6 \pm 3.16$ & $31.6 \pm 2.99$ & $37.2 \pm 3.43$ & - & - & 110 \\
\hline İlgüy ve ark. 2017 & KIBT (Retrospektif) & $31.09 \pm 2.36$ & $35.62 \pm 2.43$ & $32.69 \pm 2.29$ & $37.79 \pm 2.25$ & - & - & 161 \\
\hline $\begin{array}{l}\text { ColmenaresGonzales } \\
\text { ve ark. } 2019\end{array}$ & $\begin{array}{l}\text { Anatomi } \\
\text { (Düzlem grafi) }\end{array}$ & $33.63 \pm 2.19$ & $36.88 \pm 2.09$ & $35.45 \pm 1.86$ & $40.98 \pm 2.19$ & - & - & 115 \\
\hline Cappella ve ark. 2020 & Anatomi & $30.0 \pm 2.0$ & $35.0 \pm 2.0$ & $31.0 \pm 3.0$ & $37.0 \pm 3.0$ & - & - & 80 \\
\hline Bayrak ve Bulut 2019 & KIBT (Retrospektif) & $36.25 \pm 3.48$ & $32.26 \pm 4.17$ & $37.07 \pm 4.36$ & $33.60 \pm 4.75$ & - & - & 412 \\
\hline Akay ve ark. 2017 & KIBT (Retrospektif) & $29.78 \pm 2.05$ & $34.66 \pm 2.31$ & $31.26 \pm 2.41$ & $36.43 \pm 2.32$ & - & - & 190 \\
\hline $\begin{array}{l}\text { Tambawala ve ark. } \\
2016\end{array}$ & KIBT (Retrospektif) & $29.16 \pm 2.53$ & $34.46 \pm 2.38$ & $30.80 \pm 2.51$ & $36.22 \pm 2.33$ & - & - & 226 \\
\hline Uthman ve ark. 2012 & Helical BT & $27.3 \pm 2.2$ & $32.9 \pm 2.0$ & $29.5 \pm 2.5$ & $34.9 \pm 2.0$ & & & 88 \\
\hline Sindel ve ark. 1989 & Anatomi & - & - & - & - & $3.04 \pm 0.27^{*}$ & $3.63 \pm 0.27^{*}$ & 95 \\
\hline
\end{tabular}


Maksiller alveolün maksimum genişliği ve uzunluğu bu çalışmada kadınlarda sırasıyla ortalama $55.4 \pm 2.98 \mathrm{~mm}$ ve $46.8 \pm 2.80 \mathrm{~mm}$; erkeklerde sırasıyla ortalama $57.4 \pm 3.37 \mathrm{~mm}$ ve $49.0 \pm 2.54 \mathrm{~mm}$ olarak hesaplandı. Cappella ve ark18 çalışmasında ise kadınlarda sırasıyla ortalama $54.0 \pm 5 \mathrm{~mm}$ ve $49.0 \pm 4 \mathrm{~mm}$; erkeklerde sirasiyla ortalama $56.0 \pm 6 \mathrm{~mm}$ ve $51.0 \pm 5 \mathrm{~mm}$ olarak bildirilmiştir. Bu çalışmada cinsiyetler arasında alveol genişliği $(p=0.002)$ ve uzunluğu $(p<0.001)$ için oldukça anlamlı fark izlenmiştir. Her iki çalışmada ortalama değerlerin benzer ranjda olmasına rağmen Cappella ve ark. ${ }^{18}$ çalışmasında cinsiyetler arasında anlamlı fark izlenmedi (her biri için p>0.05). Ramamoorthy ve ark. ${ }^{23}$ maksiller alveoler uzunluğun cinsiyet belirleyiciliğinde bir faktör olduğunu $(p=0.001)$; Dayal ve ark. ${ }^{24}$ ile Franklin ve ark. ${ }^{25}$ maksiller alveoler genişliğin (sırasıyla $p=0.000$ ve $p<0.001$ ) cinsiyet için belirleyici olduğunu belirtmişlerdir. Çalışmalarda erkeklerde değerler daha yüksek olarak bulunmuştur.

Bizigomatik genişlik tüm ölçümlerle; foramen uzunluk ve genişliği ile maksiller uzunluk ve genişlik birbirleri ile çok güçlü korelasyon göstermiştir. Ayrıca sagital yönde iki ölçüm olan maksiller uzunluk ve foramen magnum uzunluğu arasında güçlü bir ilişki izlenmiştir. Foramen magnum uzunluğu ve genişliği ile kraniyum ölçümleri arasında 4,62 oranında bir ilişki tanımlayan ve literatür bilgilerle destekleyen Ulcay ve ark'nın ${ }^{11}$ çalışması göz önüne alındığında bu çalışmanın verilerinin de başka çalışmalar için bir veri havuzu oluşturabileceği ön görülmektedir.

Bu çalışmada her yaş grubundan eşit sayıda kadın ve erkeğe ait görüntülerde çalışılmış olması, ölçüm ve değerlendirmelerin tekrarlanması, analizlerde sonuçların uyumlu olarak izlenmiş olması ve literatürde rapor edilen sonuçlarla benzer veri aralığında sonuçlara ulaşılmasının çalışmanın küçük bir popülasyonda yapılması dezavantajının üstesinden geldiği düşünülmektedir.

\section{SONUÇ}

Tıbbi radyoloji ve üç boyutlu sistemlerin adli bilimlerde kullanımı son dönemlerde tercih edilmektedir. Kişilerin tıbbi nedenlerle çekilmiş tomografik görüntüleri olmayabilir. Bununla beraber bu çalışmanın sonuçları maksillofasiyal değerlendirmeler için çekilmiş olan KIBT görüntülerinin de kimlik ve cinsiyet tespiti için kullanılabilecek önemli veriler içerdiğini göstermektedir. Adli radyolojide sadece dental değil, maksillofasiyal radyolojik inceleme görüntüleri de konsültasyon açısından önem taşımaktadır.

\section{TEŞEKKÜR}

$\mathrm{Bu}$ çalışmanın istatistiksel analizindeki katkıları nedeniyle Dr. Muzaffer BiLGiN'e teşekkür ederim. 


\section{KAYNAKLAR}

1. Harorlı A. Dişlerin ve çenelerin gelişim bozuklukları ve diş çürükleri. İçinde: Ağız, Diş ve Çene Radyolojisi, 1. Baskı. İstanbul: Nobel Matbaacılık, 2014.

2. Harorlı A. Metabolik ve endokrin kemik hastalıkları. İçinde: Ağız, Diş ve Çene Radyolojisi, 1. Baskı. İstanbul: Nobel Matbaacilık, 2014.

3. Licata M, Tosi A, Ciliberti R, Badino R, Pinto A. Role of radiology in the assessment of skeletons from archelogical sites. Semin Ultrasound CT MR 2018;40:127.

4. Canger EM, Arslan S. Adli diş hekimliğinde radyolojinin kullanımı. Atatürk Üniv Diş Hek Fak Derg 2013;23:252-60.

5. Decker SJ, Braileanu M, Dey C, Lenchik L, Pickup M, Powell J, et al. Forensic radiology: A primer. Acta Radiol 2019;26:820-30.

6. Guglielmi G, Nasuto M, Pinto A. Forensic and medicolegal radiology: challenges, issues and new perspectives. Radiol Med 2015;120:777-8.

7. Ekizoglu O, Hocaoglu E, Inci E, Can IO, Solmaz D, Aksoy $S$ et al. Assessment of sex in a modern Turkish population using cranial anthropometric parameters. Leg Med (Tokyo). 2016;21:45-52.

8. Tellioglu AM, Durum Y, Gok M, Karakas S, Polat AG, Karaman CZ. Suitability of foramen magnum measurements in sex determination and their clinical significance. Folia Morphol (Warsz) 2018;77:99-104.

9. Güneş EB, Vatansever A. Türk toplumunda foramen magnum ve kafa tabanındaki oluşumların ilişkileri. Kafkas J Med Sci 2018;8:207-13.

10. Meral O, Toklu BB, Meydan R, Kaya A, Karadayı B, Acar $T$. Sex estimation from foramen magnum parameters in adult Turkish population: A computed tomographic study. Leg Med (Tokyo) 2020;47:101775.

11. Ulcay T, Kamaka B, Görgülü Ö, Uzun A, Aycan K. A golden ratio for foramen magnum: an anatomical pilot study 2021 Feb 26. doi: 10.5603/FM.a2021.0018. Online ahead of print.

12. Gövsa F, Özer MA, Çelik S, Ozmutaf NM. Threedimensional anatomical landmarks of the foramen magnum for the craniovertebral junction. J Craniofac Surg 2011;22:1073-6.

13. Chethan P, Prakash KG, Murlimanju BV, Prashanth KU, Prabhu LV, Saralaya VV, et al. Morphological analysis and morphometry of the foramen magnum: An anatomical investigation. Turk Neurosurg 2012;22:416-9.

14. Sindel M, Özkan O, Uçar Y, Demir S. Foramen Magnum'un Anatomik Varyasyonları. Akd Ün Tıp Fak Derg 1989;6:97-102.

15. Murshed KA, Çiçekçibaşı AE, Tuncer I. Morphometric evaluation of the foramen magnum and variations in its shape: A study on computerized tomographic images of normal adults. Turk J Med Sci 2003;33:301-6.

16. İlgüy $D$, İlgüy $M$, Ersan N, Dölekoğlu S, Fişekçioğlu $E$. Measurements of the foramen magnum and mandible in relation to sex using CBCT. J Forensic Sci 2014;59:6015.
17. González-Colmenares G, Sanabria Medina C, RojasSánchez MP, León K, Malpud A. Sex estimation from skull base radiographs in a contemporary Colombian population. J Forensic Leg Med 2019;62:77-81.

18. Cappella A, Gibelli D, Vitale A, Zago M, Dolci C, Sforza $C$, et al. Preliminary study on sexual dimorphism of metric traits of cranium and mandible in a modern Italian skeletal population and review of population literature. Leg Med (Tokyo) 2020;44:101695.

19. Bayrak S, Bulut DG. Assessment of foramen magnum and clivus for estimation of age and gender using cone-beam CT. Atatürk Üniv Diş Hek Fak Derg 2019;29;244-51.

20. Akay G, Güngör K, Peker I. Morphometric analysis of the foramen magnum using cone beam computed tomography. Turk J Med Sci 2017;47:1715-22.

21. Tambawala SS, Karjodkar FR, Sansare K, Prakash N, Dora AC. Sexual dimorphism of foramen magnum using cone beam computed tomography. J Forensic Leg Med 2016;44:29-34.

22. Uthman AT, Al-Rawi NH, Al-Timimi JF. Evaluation of foramen magnum in gender determination using helical CT scanning. Dentomaxillofac radiol 2012;41:197-202.

23. Ramamoorthy B, Pai MM, Prabhu LV, Muralimanju BV, Rai R. Assessment of craniometric traits in South Indian dry skulls for sex determination. J Forensic Leg Med 2016;37:8-14.

24. Dayal MR, Spocter MA, Bidmos MA. An assessment of sex using the skull of black South Africans by discriminant function analysis. Homo 2008;59:209-21.

25. Franklin D, Cardini A, Flavel A, Kuliukas A. Estimation of sex from cranial measurements in a Western Australian population. Forensic Sci Int 2013;229:158.e1-8.

Yazışma Adresi:

Esra YEŞiLOVA

Eskişehir Osmangazi Üniversitesi

Diş Hekimliği Fakültesi

Ağız Diş ve Çene Radyolojisi AD.

Eskişehir, Türkiye

Tel : +90222 23937 50/4452

E Posta : dtesra@hotmail.com 